\title{
Delayed Traumatic Intracerebellar Hematoma: Correlation Between the Location of the Hematoma and the Pre-existing Cerebellar Contusion -Case Report-
}

\author{
Kazuya NAGATA, Takaki ISHIKAWA*, Toshio ISHIKAWA*, \\ Taku SHIGENO*, Nobutaka KAWAHARA**, Takao ASANO* \\ and Kintomo TAKAKURA
}

\begin{abstract}
Department of Neurosurgery, Faculty of Medicine, University of Tokyo, Tokyo; Departments of ${ }^{*}$ Neurosurgery and ${ }^{* *}$ Emergency Medicine, Saitama Medical Center, Saitama Medical School, Kawagoe, Saitama
\end{abstract}

\begin{abstract}
A rare case of delayed traumatic intracerebellar hematoma (DTIClH) in a 54-year-old male achieved an excellent outcome without surgery. Analysis of this case and other reported cases suggests that DTIClH occurs in two types: Group I with hematoma developing in previously contused areas, and Group II with hematoma developing in areas appearing normal on the initial computed tomographic scan. Group I hematomas occurred in the cerebellar cortex, but Group II hematomas occurred in the subcortical region or vermis where direct impact is less likely to have an effect. This suggests different mechanisms of development for DTICIH.
\end{abstract}

Key words: head injury, delayed traumatic intracerebellar hematoma, computed tomography, posterior fossa, cerebral contusion

\section{Introduction}

Traumatic hematomas in the posterior fossa are rare, accounting for $3.3-6 \%$ of all head injuries. ${ }^{1,22,24,29)}$ Traumatic intracerebellar hematoma is particularly rare, with only about 100 reported cases, $0.6-0.82 \%$ of the total. ${ }^{13,15-18,21,24,26)}$

Delayed traumatic intracerebral hematoma (DTICH) is a clinical entity demonstrated by computed tomography (CT), in which hematoma develops several hours after trauma..$^{4,8,9,11,25,28)}$ In contrast, only 13 cases of delayed traumatic intracerebellar hematoma (DTIClH) have been reported. ${ }^{12,14-16,19,20,23,27)}$ DTIClH has an unfavorable prognosis because the delayed-onset mass lesion occurs in a physiologically limited space, the posterior fossa. We experienced a case of DTIClH followed by an unusually favorable course without surgical exploration. Ours and previous cases are compared and the possible mechanism responsible for delayed intracerebellar hematoma is discussed.

\section{Case Report}

This 54-year-old male fell down a staircase and struck his occiput while intoxicated. He lost consciousness and was admitted to our hospital 30 minutes later. On admission, he was deeply comatose with right mydriasis. His Glasgow Coma Scale score was 4 (E-1, V-2, M-1). An initial CT scan, however, revealed no intracranial hematoma or brain swelling (Fig. 1 left). Skull x-ray films were also normal.

Conservative treatment, including administration of hyperosmotic agents and hyperventilation under oral intubation, was initiated. He gradually regained consciousness. Six hours after admission, he was 

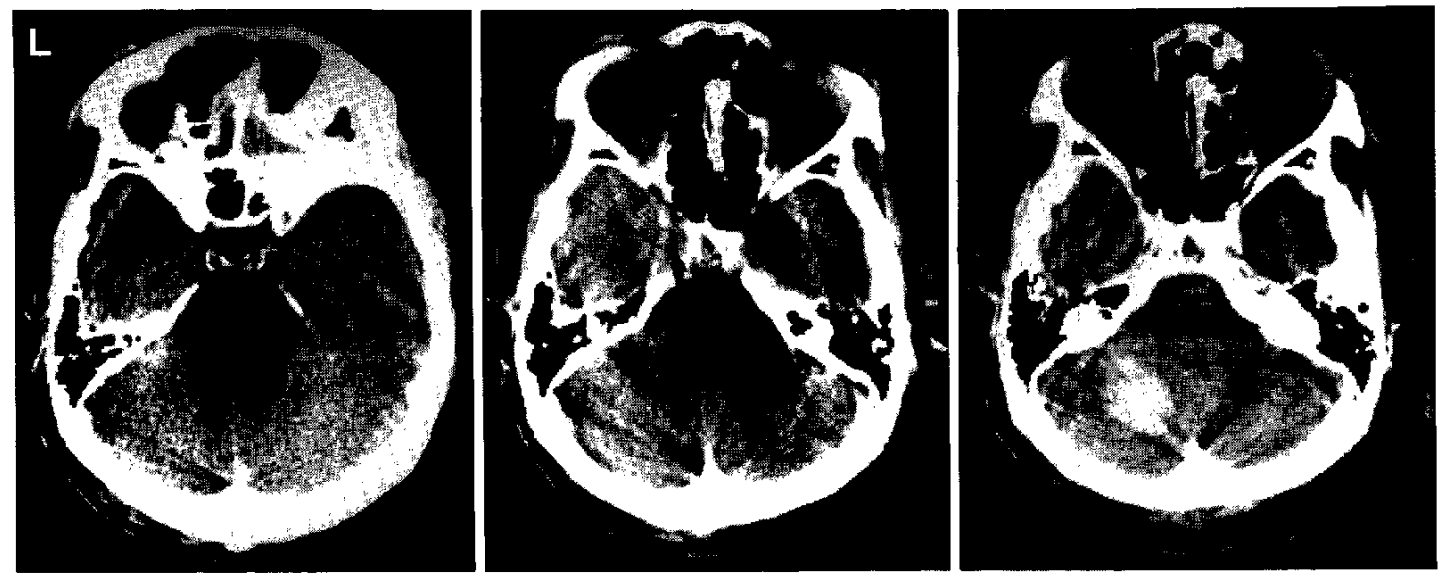

Fig. 1 Sequential CT scans. left: On admission, no abnormality is detected. center: Six hours after admission, there is still no abnormality. right: Seventeen hours after admission, a 3-cm hematoma in the left cerebellar hemisphere is seen.

slightly lethargic, oriented to people, and responsive to verbal commands. A CT scan still revealed no abnormalities (Fig. 1 center). However, a CT scan obtained 17 hours after admission revealed a $3-\mathrm{cm}$ hematoma in the left cerebellar hemisphere (Fig. 1 right), although he was almost fully alert with only mild truncal ataxia. There was no evidence of obstruction of cerebrospinal fluid pathways. No abnormal increase in systemic blood pressure, or attacks of vertigo or vomiting were noted during this period.

Since his clinical condition was apparently improving, nonsurgical management was carried out under strict neurological observation. Vascular lesions were not the origin of the spontaneous cerebellar hemorrhage as vertebral angiograms failed to detect any vascular malformations or berry aneurysms. He continued to improve over the following weeks. He was discharged on the 20th hospital day with hardly any neurological deficit. Two months later, he could play golf almost as well as before.

\section{Discussion}

Before the introduction of CT, delayed intracerebellar hematoma was difficult to diagnose correctly. Only the two cases of Baratham and Dennyson ${ }^{3)}$ had been reported in the literature. Now, patients can be followed up with repeat CT scanning, leading to an increased number of cases reported. Table 1 summarizes the 13 reported cases of DTIClH with CT diagnoses. ${ }^{12,14-16,19,20,23,27)}$ The mean age is 25.5 years, and no sex predominance was observed. The delay between the trauma and hematoma oc- currence ranged from 4 hours to 4 days, with a mean of 31.5 hours.

The mechanism responsible for delayed intraparenchymal hematoma is still controversial. Evans and Scheinker ${ }^{6)}$ proposed a sequence of vasoparalysis in the contused brain causing increased endothelial cell permeability followed by diapedesis and extravasation resulting in the formation of intracerebral hematoma based on autopsy studies of acute traumatic intracerebral hematoma. Morin and Pitts $^{10)}$ first applied this hypothesis to the occurrence of DTIClH. Diaz et al. ${ }^{51}$ and Kobayashi et al. ${ }^{9}$ demonstrated extravasation in the contused area on the basis of postcontrast CT studies. Aruga et al. ${ }^{2)}$ and Fukamachi et $a l^{7)}$ proposed that petechial hemorrhages in a contused region gradually fuse to form a large hematoma based on clinical observations. Young et $a l .^{28)}$ reported that hematomas always developed in previously contused areas in their series of 15 DTICH cases.

In contrast, Tsubokawa et al. ${ }^{25)}$ found that in 17 of 34 cases, DTICH developed in a previously normal area. Their autopsy study showed that the hematoma contained several thrombosed vessels, sometimes with lymphocytic infiltration, in such cases. Many dilated vessels with perivascular leakage of the plasma component and ruptured small vessels were present in the boundary of the hematoma. They proposed that hyperoxidation caused by local cerebral circulation disorders was a possible mechanism of DTICH based on these observations.

Analysis of $C$ T scans in 11 of the 14 reported cases of DTICIH, including ours, shows that the hematoma location may be divided into two groups 
Table 1 Summary of reported cases of DTIClH

\begin{tabular}{|c|c|c|c|c|c|c|c|c|c|c|}
\hline $\begin{array}{l}\text { Case } \\
\text { No. }\end{array}$ & Author (Year) & $\begin{array}{l}\text { Age } \\
\text { (yrs) }\end{array}$ & Sex & $\begin{array}{l}\text { Consciousness } \\
\text { on admission }\end{array}$ & $\begin{array}{l}\text { Site of } \\
\text { impact }\end{array}$ & $\begin{array}{l}\text { Contusion } \\
\text { on } \\
\text { initial } \mathrm{CT}\end{array}$ & $\begin{array}{c}\text { Fracture } \\
\text { on skull } \\
\text { x-ray }\end{array}$ & Duration $^{*}$ & $\begin{array}{c}\text { Opera- } \\
\text { tion }\end{array}$ & Outcome $\mathrm{e}^{* * *}$ \\
\hline 1 & $\begin{array}{l}\text { Olin et al. } \\
\qquad(1980)^{12}\end{array}$ & elderly & $\mathrm{F}$ & alert & forehead & + & - & 3 days & + & $\mathrm{D}$ \\
\hline 2 & $\begin{array}{c}\text { Sakuta and Sakuta } \\
(1980)^{15}\end{array}$ & 7 & F & drowsy & occiput & - & + & 4 hrs & + & FR \\
\hline 3 & $\begin{array}{l}\text { Pozzati et al. } \\
\qquad(1981)^{14 !}\end{array}$ & 16 & $\mathrm{M}$ & deep coma & occiput & + & - & $24 \mathrm{hrs}$ & - & FR \\
\hline 4 & $\begin{array}{l}\text { Tibbs et al. } \\
(1981)^{23)}\end{array}$ & 30 & $\mathrm{M}$ & lethargic & occiput & + & + & $12 \mathrm{hrs}$ & + & GR \\
\hline 5 & $\begin{array}{c}\text { Shigemori et al. } \\
(1981)^{20)}\end{array}$ & 38 & $\mathbf{M}$ & stupor & occiput & + & + & $36 \mathrm{hrs}$ & + & $\mathrm{D}$ \\
\hline 6 & $\begin{array}{l}\text { Seida et al. } \\
\quad(1986)^{19 !}\end{array}$ & 9 & $\mathrm{~F}$ & GCS 14 & occiput & - & + & $4 \mathrm{hrs}$ & + & $\mathrm{D}$ \\
\hline 7 & $\begin{array}{l}\text { Sato et al. } \\
\quad(1987)^{(6)}\end{array}$ & 71 & $\mathbf{M}$ & GCS 12 & occiput & + & ND & $6 \mathrm{hrs}$ & + & PVS \\
\hline 8 & $\begin{array}{l}\text { Yokota et al. } \\
(1988)^{27)}\end{array}$ & 9 & M & GCS 9 & occiput & - & + & $14 \mathrm{hrs}$ & + & MD \\
\hline 9 & & 23 & M & $\operatorname{GCS} 6$ & occiput & ND & - & 3 days & - & PVS \\
\hline 10 & & 1 & $\mathbf{F}$ & $\operatorname{GCS} 6$ & frontal & ND & + & 4 days & - & D \\
\hline 11 & & 7 & F & $\operatorname{GCS} 3$ & occiput & - & + & $12 \mathrm{hrs}$ & + & $\mathrm{D}$ \\
\hline 12 & & 65 & $\mathbf{F}$ & GCS 14 & occiput & - & + & $24 \mathrm{hrs}$ & + & SD \\
\hline 13 & & 2 & M & $\operatorname{GCS} 5$ & occiput & ND & - & 48 hrs & - & SD \\
\hline 14 & Present case & 54 & M & $\operatorname{GCS} 4$ & occiput & - & - & $17 \mathrm{hrs}$ & - & FR \\
\hline
\end{tabular}

${ }^{*}$ Between trauma and hematoma appearance. ${ }^{* *}$ Based on Glasgow Outcome Scale: D indicates death; FR, full recovery; GR, good recovery; MD, moderate disability; PVS, persistent vegetative state; SD, severe disability. GCS: Glasgow Coma Scale, ND: not described.
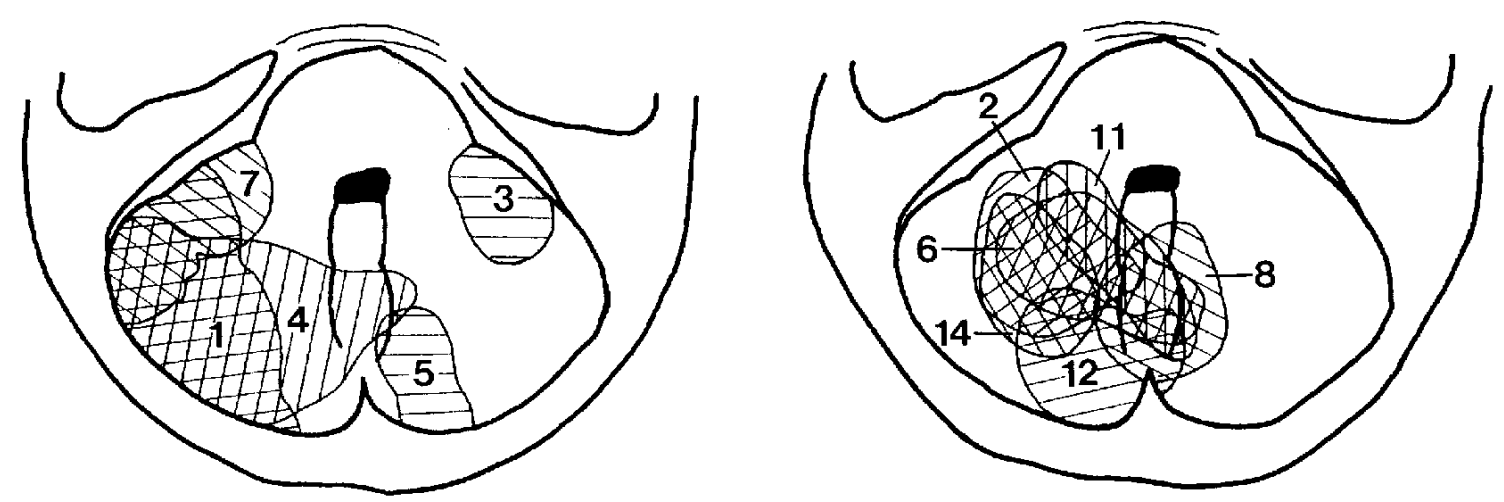

Fig. 2 Types of DTIClH and location. left: Group I hematoma in the previously contused area in the cerebellar cortex. right: Group II hematoma in an initially normal area in the subcortical region or vermis. Numerals in the figure indicate Case Nos. in Table 1.

(Fig. 2). Five cases (45.5\%) in Group I demonstrated DTIClH in a previously contused area, and six $(54.5 \%)$ in Group II developed hematoma in an area appearing normal on the initial CT scan. All Group I hematomas developed in the cerebellar cortex, while Group II hematomas always occurred in the subcortical region or vermis where the direct impact is less likely to have an effect.

Laterally located hemorrhage with no involvement of the deep cerebellar nuclei distinguishes traumatic from spontaneous hematomas, ${ }^{2)}$ but DTIClH sometimes develops in areas apparently normal by CT scanning. The CT scan is often unreliable for interpretation of the posterior fossa, particularly in injured patients scanned under suboptimum conditions. However, the latest developments in highresolution CT scanning can demonstrate a small lesion in the posterior fossa. In our case, the initial CT scan demonstrated no abnormal lesion in the posterior fossa. The development of Group II hematomas 
is apparently different from spontaneous cerebellar hemorrhage. Our case, in Group II, had no history of hypertension and abnormally high systemic blood pressure did not occur during hospitalization. Clinically, no attacks of vertigo or nausea occurred. Vertebral angiograms demonstrated no vascular abnormality. These findings strongly suggest that, in our case, the hematoma was not spontaneous but was caused by the initial head trauma. Therefore, trauma can cause subcortical or deep hematomas, frequently in an area appearing normal on the initial CT scan. This suggests that DTIClH is not simply the result of fusion of small contusional hematomas as in Group I hematomas. The vascular factors proposed by Tsubokawa et l. $^{25)}$ may be important in the formation of delayed traumatic hematoma. More advanced magnetic resonance imaging gives a clearer image of the posterior fossa, and will provide more evidence about this problem in the near future.

DTIClH usually has an unfavorable outcome. Five of the 14 reported cases died, a mortality of $35.7 \%$. The outcome for five survivors was moderate or severe disability based on the Glasgow Outcome Scale. Only four cases fully recovered, two patients after surgical decompression, and the other two without surgery. Their mean age was 26.8 years, and the mean time from trauma to hematoma appearance was 14.3 hours, neither significantly different from the group with unfavorable outcomes. The initial consciousness levels were deep coma in two, lethargy in one, and drowsiness in one, showing no correlation between outcome and initial consciousness level. There were two Group I and two Group II hematomas, so the outcome was not dependent on the site of the hematoma. Our case achieved a favorable outcome without surgery, but DTIClH is potentially fatal. Early diagnosis based on strict observation and repeat CT scanning will lead to better results.

\section{References}

1) Anegawa S, Yoshimura K, Kawai K, Kuramoto S: Traumatic intracerebellar hematoma. A case report and the review of the literature. No Shinkei Geka 7: 911-915, 1979 (in Japanese)

2) Aruga T, Masuzawa H, Mizutani H, Mii K, Eguchi T, Sano K: Evolution of traumatic intracerebral hematoma. Neurol Med Chir (Tokyo) 19: 459-466, 1979 (in Japanese)

3) Baratham G, Dennyson WG: Delayed traumatic intracerebral haemorrhage. $J$ Neurol Neurosurg Psychiatry 35: 698-706, 1972

4) Brown FD, Mullan S, Duda EE: Delayed traumatic intracerebral hematomas. Report of three cases. $J$ Neurosurg 48: 1019-1022, 1978

5) Diaz FG, Yock DH Jr, Larson D, Rockswold GL: Early diagnosis of delayed posttraumatic intracerebral hematomas. I Neurosurg 50: 217-223, 1979

6) Evans JP, Scheinker IM: Histologic studies of the brain following head trauma, II. Posttraumatic petechial and massive intracerebral hemorrhage. $J$ Neurosurg 3: 101-113, 1946

7) Fukamachi A, Kohno K, Wakao T, Tasaki $T$, Koizumi H, Nagaseki Y: Traumatic intracerebral hematomas. A classification according to the dynamic changes on sequential CT's. Neurol Med Chir (Tokyo) 19: 1039-1051, 1979 (in Japanese)

8) Kaufman HH, Moake JL, Olson JK, Miner ME, duCret RP, Pruessner JL, Gildenberg PL: Delayed and recurrent intracranial hematomas related to disseminated intravascular clotting and fibrinolysis in head injury. Neurosurgery 7: 445-449, 1980

9) Kobayashi S, Nakazawa S, Yokota $H$, Isayama $K$, Yajima K, Otsuka T: Experience with contrastenhanced $C T$ in delayed traumatic intracerebral hematoma. CT Kenkyu 6: 97-103, 1984 (in Japanese)

10) Morin MA, Pitts FW: Delayed apoplexy following head injury ("traumatishe Spat-Apoplexie"). $J$ Neurosurg 33: 542-547, 1970

11) Ninchoji T, Uemura K, Shimoyama I, Hinokuma $K$, Bun T, Nakajima S: Traumatic intracerebral hematomas of delayed onset. Acta Neurochir (Wien) 71: 69-90, 1984

12) Olin MS, Young HA, Schmidek HH: Contrecoup intracerebellar hemorrhage: Report of a case. Neurosurgery 7: 271-273, 1980

13) Pozzati E, Grossi C, Padovani R: Traumatic intracerebellar hematomas. J Neurosurg 56: 691-694, 1982

14) Pozzati E, Piazza G, Padovani R, Gaist G: Benign traumatic intracerebellar hematoma. Neurosurgery 8: $102-103,1981$

15) Sakuta $Y$, Sakuta $Y$ : Traumatic acute intracerebellar hematoma. A case of complete recovery. No Shinkei Geka 8: 1087-1092, 1980 (in Japanese)

16) Sato K, Hinokuma K, Matsuzawa $Y$, Takehara S, Uemura K, Ninchoji T, Shimoyama I: Clinical study of traumatic cerebellar contusion. No Shinkei Geka 15: 1285-1289, 1987 (in Japanese)

17) Sato $O$, Kuwabara $T$, Nakamura $N$ : On the traumatic hematoma of the posterior fossa. No To Shinkei 17: 437-448, 1965 (in Japanese)

18) Satoh T, Yamamoto $Y$, Asari S: Traumatic acute intracerebellar hematoma: Especially the value of CT follow-up. No Shinkei Geka 11: 101-106, 1983 (in Japanese)

19) Seida $M$, Ito $U$, Kito $K$, Tomida $S$, Inaba $Y$ : Traumatic cerebellar hematoma in children. Report of two cases. Neurol Med Chir (Tokyo) 26: 318-322, 1986 (in Japanese)

20) Shigemori $M$, Shirahama $M$, Tokutomi $T$, Hara $K$, Yamamoto F: Delayed development of traumatic in- 
tracerebellar hematoma. Case report. Significance of serial CT scan and management. Neurol Med Chir (Tokyo) 21: 427-431, 1981 (in. Japanese)

21) Sokol JH, Rowed DW: Traumatic intracerebellar haematoma. Surg Neurol 10: 340-341, 1978

22) St John JN, French BN: Traumatic hematomas of the posterior fossa. A clinicopathological spectrum. Surg Neurol 25: 457-466, 1986

23) Tibbs PA, Goldstein SJ, Smithson JR Jr: Delayed traumatic intracerebellar hematoma. Surg Neurol 16: 309-311, 1981

24) Tsai FY, Teal JS, Itabashi HH, Huprich JE, Hieshima GB, Segall HD: Computed tomography of posterior fossa trauma. J Comput Assist Tomogr 4: 291-305, 1980

25) Tsubokawa T, Yamada J, Tomizawa N, Goto $T$, Shinozaki $H$, Moriyasu $\mathrm{N}$ : Classification of traumatic intracerebral hematoma by repeated $\mathrm{CT}$ scan and clinical course. Neurol Med Chir (Tokyo) 19: 1127-1137, 1979 (in Japanese)

26) Yokota $H$, Kobayashi $S$, Yajima $K$, Nakazawa $S$,
Yano M, Yamamoto Y, Otsuka T: Clinical study of traumatic intracerebellar hemorrhage. Neurol $\mathrm{Med}$ Chir (Tokyo) 25: 844-849, 1985 (in Japanese)

27) Yokota H, Mizunari $T$, Kuzuhara M, Kobayashi S, Yajima K, Nakazawa S, Yano M, Yamamoto Y: Traumatic delayed intracerebellar hematoma. Neurol Med Chir (Tokyo) 28: 886-890, 1988 (in Japanese)

28) Young HA, Gleave JRW, Schmidek HH, Gregory S: Delayed traumatic intracerebral hematoma: Report of 15 cases operatively treated. Neurosurgery 14: 2225,1984

29) Zuccarello M, Andrioli GC, Fiore DL, Longatti PL, Pardatscher K, Zampieri P: Traumatic posterior fossa haemorrhage in children. Acta Neurochir (Wien) 62: 79-85, 1982

Address reprint requests to: K. Nagata, M.D., Department of Neurosurgery, Shin-Tokyo Hospital, 473-1 Nemoto, Matsudo, Chiba 271, Japan. 